\title{
Lack of mate selectivity for genetic compatibility within the red brocket deer Mazama americana complex
}

\author{
Juan Carranza a,b,c,*, Mar Roldán a , José Maurício Barbanti Duarte ${ }^{a}$ \\ a Núcleo de Pesquisa e Conservação de Cervídeos (NUPECCE), Universidade Estadual Paulista (Unesp), Faculdade de Ciências Agrárias e Veterinárias, \\ Jaboticabal, Brazil \\ ${ }^{\mathrm{b}}$ Ungulate Research Unit, Cátedra de Recursos Cinegéticos y Piscícolas (CRCP), Universidad de Córdoba, 14071 Córdoba, Spain \\ ${ }^{\mathrm{c}}$ Medicina Veterinaria y Zootecnia, Universidad Agraria del Ecuador, Guayaquil, Ecuador
}

\section{A R T I C L E I N F O}

\section{Article history:}

Received 14 March 2017

Accepted 23 September 2017

Handled by Frank E. Zachos

Available online 4 November 2017

\section{Keywords:}

Premating barriers

Mazama americana

Speciation

Mating

Courtship behaviour

Mate choice

No-choice experiments

Cytotypes

\begin{abstract}
A B S T R A C T
Red brocket deer Mazama americana includes at least two lineages that differ at the level of karyotypes and phylogenetic relationships based on mtDNA. Also, hybrids between them have been proved to be nonviable or infertile. Since successful breeding is hampered, we expect selection to have produced a precopulatory barrier between these lineages based on courtship behaviour, to prevent investment in unsuccessful breeding. Here we made experiments with specimens in captivity to investigate mating preferences for partners belonging to the same or different karyotypes or lineages, along with a whitetailed deer buck (Odocoileous virginianus) as an outgroup control. Behaviours were video recorded and analysed by using Generalized Linear Mixed Models, with the interacting females and males as random subjects. The results show that although red brocket females never accepted copulations with the control male, trials involving pairs of red brocket deer may or may not end with copulation regardless as to whether the partners belonged to the same or different lineages. Although some male and female behaviours differed when pairs belonged to the same or different lineages, our results do not support the existence of a precopulatory barrier between lineages in the red brocket deer complex. We discuss the implications for sympatric speciation and species conservation.
\end{abstract}

(c) 2017 Deutsche Gesellschaft für Säugetierkunde. Published by Elsevier GmbH. All rights reserved.

\section{Introduction}

The processes of sympatric speciation have puzzled evolutionary biologists for decades (Coyne and Orr, 2004; Dobzhansky, 1937; Futuyma, 2005; Mayr, 1963). In the absence of geographical barriers that produce isolation, simple distance in geographically continuous areas has been shown to allow the genetic differentiation of populations up to reproductive isolation (Futuyma, 2005). One example are the ring species, or series of populations wrapping around a geographical barrier where the two terminal populations do not exchange genes directly but are connected by a chain of interbreeding populations (Irwin et al., 2001). But distant populations in fairly homogeneous areas may also suffer differentiation processes in a chain of intermediate forms. These changes may be adaptive but also random, the latter being especially relevant when ecological conditions maintain over large geographic areas. One of

\footnotetext{
* Corresponding author at: Ungulate Research Unit, Cátedra de Recursos Cinegéticos y Piscícolas (CRCP), Universidad de Córdoba, 14071 Córdoba, Spain.

E-mail address: jcarranza@uco.es (J. Carranza).
}

these forms of random processes of change is karyotypic evolution. In some taxa, karyotypes tend to experience changes within short periods of time giving rise to reproductive incompatibility, such as the reported rapid chromosomal evolution in mice (BrittonDavidian et al., 2000). Chromosomal evolution may be a source of rapid, non-adaptive changes producing accelerated rates of radiations, but examples are very scarce for this type of speciation processes (Britton-Davidian et al., 2000). Populations differing in chromosomal composition can produce hybrids that may be sterile or infertile owing to the complex chromosomal configurations that would occur in meiosis (Baker and Bickham, 1986). Once the chromosomes have differentiated after a short period of time (e.g. as short as 500 years in mice: Britton-Davidian et al., 2000), a question arises about the consequences for other reproductive processes. For example, post-zygotic reproductive isolation such as karyotypic divergence is expected to promote adaptive pre-zygotic barriers since resources devoted to offspring production will have no fitness return.

The red brocket deer (Mazama americana) is one of the best examples for a large mammal of karyotypic diversification leading to true sympatric speciation (see Amato et al., 2000, and Huang 
et al., 2006, for a similar case in Muntiacus reevesi). Members of this species complex (Abril et al., 2010; Aquino et al., 2013; Cursino et al., 2014), currently occur in forest habitats (Bodmer, 1997; Duarte, 1996; Escobedo-Morales et al., 2016; Varela et al., 2010) throughout a wide distribution range from México to the north of Argentina (Eisemberg, 1989; Emmons, 1990). Earlier studies described up to eight different species within the red brocket deer complex (Allen, 1915) that were later included in one with a variable number (9-15) of subspecies (Cabrera, 1960; Czernay, 1987; Rossi, 2000). A cryptic species, the small red brocket deer $M$. bororo, was initially included within the complex but lately identified as a separated species based on chromosomal and morphological differences (Duarte, 1996; Duarte and Merino, 1997; Duarte and Jorge, 2003). More recent work based on cytogenetics and mtDNA sequencing have provided improved tools for the assessment of taxonomic diversity within the complex and its relationships with other neotropical deer, evidencing the explosive diversification during the late Pliocene (2.5-3 MYA), soon after their ancestor arrived in South America through the Panamanian land bridge, giving rise to a number of morphologically cryptic species within the red brocket clade (Duarte et al., 2008; Escobedo-Morales et al., 2016; Heckeberg et al., 2016).

The analysis of the cytogenetic evolution has recently shown the existence of two karyotypic lineages that evolved from a common ancestor by chromosomal rearrangements: Lineage A, which includes the Rondônia and Juína karyotypes; and Lineage B, which includes the Jarí, Carajás, Santarém, and Paraná karyotypes (Abril et al., 2010). Both lineages are also well differentiated at the level of mtDNA (Abril et al., 2010) and maintain reproductive isolation, with hybrids showing sterility or subfertility (Aquino et al., 2013; Cursino et al., 2014; Salviano et al., 2017). All these results clearly point to the existence of at least two separate species within the current Mazama americana specific nomination, which need to be formally described, and probably a deeper investigation could reveal further subdivisions under an ongoing process of rapid sympatric speciation based on chromosomal rearrangements (Abril et al., 2010).

Genetic compatibility is a central element in reproductive isolation and speciation (Coyne and Orr, 2004; Piálek and Albrecht, 2005) and there is increasing support for the role of sexual selection in sympatric speciation (van Doorn et al., 2009; Wagner et al., 2012). For mammalian females, the production of hybrids may entail high costs of gestation and lactation that compromise mothers' success. These potentially high costs of matings leading to subfertile hybrids are expected to fuel selection favouring pre-zygotic barriers known as reinforcement in speciation (Servedio and Noor, 2003), which may include mate choice strategies to discriminate among mating partners and reject as mates those that would give rise to less successful offspring (Andersson, 1994; Trivers, 1972).

Sexual selection has an important role in maintaining species isolation by the evolution of signal divergence between species (Ptacek, 2000), and female choice is an important mechanism for both species recognition and intraspecific mate selection (Andersson, 1994; Kokko et al., 2003). Sexual signals during courtship (Andersson 1994; Johnstone 1997), such as visual displays or sex pheromones, play a crucial role as premating barriers between closely related taxa (Ptacek, 2000; Bradbury and Vehrencamp, 2011). Little is known on the courtship behaviour and mating system of the red brocket deer. As forest dwellers, individuals are solitary, with females using mostly exclusive ranges and male ranges overlapping with those of more than one female. Although the geographic ranges of distribution for both lineages have not been delimited, the species occurs throughout a large, continuous geographic area in which interactions between members of both lineages could occur along contact zones. Here we focus on the behavioural barriers that could prevent gene flow between both
Table 1

Description of the individuals used in the study.

\begin{tabular}{llll}
\hline Individual & sex & Cytotype & Karyotypes \\
\hline 1 & $\mathrm{~F}$ & Paraná & $2 \mathrm{n}=52 / \mathrm{NF}=56$ \\
2 & $\mathrm{~F}$ & Paraná & $2 \mathrm{n}=52 / \mathrm{NF}=56$ \\
3 & $\mathrm{~F}$ & Paraná & $2 \mathrm{n}=52 / \mathrm{NF}=56$ \\
4 & $\mathrm{M}$ & Paraná & $2 \mathrm{n}=53 / \mathrm{NF}=56$ \\
5 & $\mathrm{M}$ & Paraná & $2 \mathrm{n}=53 / \mathrm{NF}=56$ \\
6 & $\mathrm{M}$ & Paraná & $2 \mathrm{n}=53 / \mathrm{NF}=56$ \\
7 & $\mathrm{M}$ & Paraná & $2 \mathrm{n}=53 / \mathrm{NF}=56$ \\
8 & $\mathrm{~F}$ & Rondônia & $2 \mathrm{n}=42 / \mathrm{NF}=49$ \\
9 & $\mathrm{M}$ & Rondônia & $2 \mathrm{n}=43 / \mathrm{NF}=49$ \\
10 & $\mathrm{M}$ & Carajás & $2 \mathrm{n}=51 / \mathrm{NF}=54$ \\
11 & $\mathrm{M}$ & Juína & $2 \mathrm{n}=44-45 / \mathrm{NF}=48$ \\
\hline
\end{tabular}

lineages. In particular, our goal was to study courtship behaviour of captive pairs during mating trials with members of the same and different karyotypic lineages, as a potential pre-mating barrier contributing to reproductive isolation between both putative species.

We were interested in testing whether the two red brocket deer lineages are fully reproductively isolated and will not engage in courtship behaviour and mating with members of the other lineage. The null hypothesis, therefore, is that there are no differences in copulation probability, and in the behaviour of males and females in couples formed by animals belonging to the same or different lineages.

\section{Material and methods}

\section{Animals}

The study used eleven adult animals from a red brocket deer species (Mazama americana), 4 females (aged 3.1-14.3-years-old, $37.5-45.2 \mathrm{~kg}$ body weight) and seven males (aged 2.9-15.3-yearsold, $37.8-41.7 \mathrm{~kg}$ body weight). These animals belonged to four different cytotypes. The experimental subjects belonged to cytotypes Juina (J) and Rondonia (R) of Lineage A, and cytotypes Paraná $(P)$ and Carajás $(C)$ of Lineage B. In particular, three of the four females belonged to the Paraná cytotype and one to Rondônia. In males, four of them belonged to the Paraná cytotype, one to Juína, one to Carajás and another one to Rondônia (see Table 1).

Seven of these animals were born in the research centre and the rest came from confiscations, either directly sent by the authorities to the research centre or after spending some period in a zoo.

Animals were maintained in individual indoor stalls visually isolated from one another, although they probably got olfactory information from each other since all of them were kept in the same building. Three of four females had previous experience with males, either mating or simply having physical proximity when assessing their oestrus status. Regarding males, only two had previous experience with females. All animals were subjected to similar management and olfactory or other casual contacts might have occurred among the individuals, so there was no evident reason for a bias towards knowledge of their own or different cytotypes. However, previous experience was obviously variable among individuals and this represents an uncontrolled variable in our experiments, hence included as random subject in the analyses (see below).

Animals were maintained in captive conditions housed individually in indoor holding areas all day (individual stalls of $12 \mathrm{~m}^{2}$ ) at the Deer Research and Conservation Centre (NUPECCE) of the Department of Animal Science of the FCAV-UNESP in Jaboticabal, São Paulo, Brazil. Animals from all cytotypes were fed ad libitum with a diet consisting of a pelleted feed (12\% crude protein, $2 \%$ crude fat, $10 \%$ crude fibre; Purina Co., Paulínia, Brazil) and approxi- 
mately $1 \mathrm{~kg} /$ animal/day of fresh alfalfa (Medicago sativa), perennial soybean (Neonotonia wightii), or mulberry branches (Morus alba). Drinking water was available ad libitum. The present study was approved by the Animal Ethics and Welfare Committee (Comitê de Ética e Bem-estar Animal, CEBEA) of the School of Agricultural and Veterinary Sciences (Faculdade de Ciências Agrárias e Veterinárias, FCAV) of São Paulo State University (UNESP), Jaboticabal, SP, Brazil.

\section{Experimental procedure}

We conducted no-choice mating trials, where a female in oestrous was sequentially exposed to different males. The order of the sequence of males was interchanged in successive oestrus for the same female. We aimed to test every individual male and female with partners from both the same and different cytotypes.

The use of two-choice or no-choice experimental procedures to test female preferences has been recently reviewed by Dougherty and Shuker (2015), highlighting the importance of the species ecology for the selection of the best experimental design. In the case of species in which females are unlikely to encounter more than one mate at a time and multiple matings occur only by contacting sequentially with potential mates, as it is the case for Mazama species, the no-choice design may be more appropriate to reduce bias in the estimation of female preferences (see also Ryan and Tailor, 2015).

\section{Manipulation of animals and conducting mating trials}

We carried out 88 mating trials, involving seven males and four females of both species, along with eight control trials with a male of the outgroup species Odocoileus virginianus. For the trials, one male was herded along the corridor to the stall with the female; the door was left open to let the male enter on his own. We then closed the door and recorded during approximately fifteen minutes (arbitrary time, but based on previous observations that indicated that it was enough to allow mating behaviour until the intensity of interactions noticeably decreased) with a video camera placed in an elevated position over the wall of the stall. Although we intended to maintain the same duration time of $15 \mathrm{~min}$ for recording the sequence in all trials, it had to be interrupted in cases of clear rejection with aggressive behaviour or any other circumstances undesirable from the point of view of animal welfare.

Females were used in trials when in oestrus. The oestrus was natural or induced. To detect oestrus, females were monitored daily by an examiner, and in some doubtful cases we used a male to see the reaction of the female. Behavioural oestrus was characterized by an increase of cervical mucus production, as well as by the lack of reflex reaction to the pressure in the pelvic region by the examiner (Curlewis et al., 1988; Zanetti et al., 2010) or when remaining still while the male attempted to court and mount her. After the first natural oestrus of a female, we normally induced subsequent cycles by applying $265 \mu \mathrm{g}$ cloprostenol (one $\mathrm{mL}$ Ciosin; Schering Plough Coopers, Brazil), a synthetic analogue of prostaglandin F2 alpha to provoke the regression of corpora lutea and restart the oestrus cycle (Shah et al., 2014).

\section{Courtship and mating behaviours}

Courtship interactions normally started with the male approaching the female. He usually headed towards her anogenital region and performed olfactory inspection. The hind might stay, withdraw or even run when this behaviour starts. After this olfactory inspection by the male, he generally showed the flehmen response. Frequently, flehmen was also performed after the femaleís urine olfaction. In case of acceptance, the hind tended to stand firmly and move her tail while the male displayed courtship behaviour and attempted to mount her.

We considered two periods within the trial, the pre-copulation period and, if copulation happened, the post-copulation period. After a post-copulation period, animals may engage again in courtship behaviours that sometimes led to more than one copulation within the same trial. Those periods when they pursued further copulations were also recorded as pre-copulation, and the beginning of these periods was identified by a significant change in their behaviour, normally by the male.

The behavioural patterns used in this study were based on our own preliminary observations and those described in the literature (Morales-Piñeyrua and Ungerfeld, 2012; Samsudewa and Capitan, 2011; Tomkins and Bryant, 1974).

For males, recorded behaviours were:

- Anogenital smelling: the actor approaches his nose to the anogenital area of the recipient.

- Head smelling: the actor approaches his nose to the head of the recipient.

- Licking: licking areas of the body, normally head, ears, neck (anogenital excluded here). It may be mutually performed by both partners.

- Initiating contact: the focal individual starts some non-aggressive interaction within courtship.

- Searching: from a separate position, the focal individual walks towards the other partner.

- Tongue flick: repeated tongue extension and retraction.

- Mounting attempts: male attempts to mount females, even from her side or head, but commonly from the rear quarters by jumping on her back and placing his slightly bent forelegs on her flanks. No intromission of the penis occurs.

- Flehmen: male flehmen response by which scents are transferred to the vomeronasal organ. The male curls back its upper lips exposing its front teeth, inhales with the nostrils usually closed, often holding this position for several seconds.

- Copulation: mounting including penis intromission and ejaculation. It was identified by the sudden movement of the male's pelvic area.

- Hitting the ground: Animals remain standing still and hit the ground with one of the forelegs.

- Rubbing the antlers: Males rub the antlers against the walls or the door of the stalls.

For females, the recorded behaviours were:

- Anogenital smelling: the actor approaches his nose to the anogenital area of the recipient.

- Head smelling: the actor approaches his nose to the head of the recipient.

- Initiating contact: the focal individual starts some non-aggressive interaction within courtship.

- Searching: from a separate position, the focal individual walks towards the other partner.

- Tongue flick: tongue extension and retraction

- Licking: licking areas of the body, normally head, ears, neck. It may be mutually performed by both partners.

- Squatting: the hind adopted the urination or defecation posture and generally urinated or defecated.

- Tail: tail fanning. Repeated movement of the tail in a horizontal plane. During motion, the tail was maintained slightly lifted.

- Hitting the ground: Animals remain standing still and hit the ground with one of the forelegs.

Additionally, we recorded the events when an individual, usually the female, performed some aggressive behaviour, actively 
rejecting the male. In these cases we ceased the trial and registered the result as mate rejection.

\section{Statistical analyses}

For data analysis we used Generalized Linear Mixed Models as implemented in SPSS v.20 (SPSS, Chicago, IL, U.S.A.). Our data file had one line per individual in a trial, hence two lines per mating trial, one for the male and another for the female.

We performed two types of models. First, we were interested in looking at the copulation outcome in trials with the different combinations of mating pairs and depending on whether they both belong to the same or different species and lineages. In this case we selected cases for one of the sexes to run the analysis, since the outcome was common to both individuals of the pair. Secondly, we were interested in the behaviours performed either by the male or by the female in the mating pair that associated with an outcome of copulation, or that occurred when both partners belonged to the same or different lineages. To perform those analyses, we selected male cases or female cases, respectively. Response variable was binary for the analyses with copulation (yes, no) and lineage (same, different) as dependent variables. In these cases we used the binomial distribution with Logit link function. Random subjects were in all cases individual females nested within males and the random effect covariance type was "variance components". When independent factors were behavioural patterns, they were introduced as absolute frequencies or time in seconds, and always the duration in seconds of the observation period was also included as a control covariate. We firstly introduced all relevant two-way interactions and thereafter used a backwards-stepwise procedure to remove non-significant interactions one by one from those with highest $\mathrm{p}$ values until the model was not improved on the basis of information criterion values (Akaike and Bayesian Criteria). We used the analytical options that the SPSS package offers for GLMM to deal with data limitations, namely (1) variable degrees of freedom across tests (Satterthwaite approximation), and (2) robust covariance estimations for the tests of fixed effects. All the main fixed effects were kept in the final model except in case of collinearity. Collinearity between covariates was treated firstly by inspection of the correlation matrix, and when the Spearman correlation coefficient was higher than 0.60 we chose the variable that resulted in the smaller information criterion values (Akaike and Bayesian Criteria).

\section{Results}

Did interactions leading to copulation depend on the species/lineage pairing?

Trials with the control species, the white-tailed deer, never led to copulation, while copulations occurred in Mazama pairs of same or different lineages (Fig. 1). The copulation outcome was not independent of the type of species/lineage pairing (chi-square $=8.698$, df $2, p=0.013$ ), but it depended only on the lack of copulations with the control species. In some trials females actively rejected the male with aggressive behaviours, and hence the trial ended. These rejection responses occurred in all pairing types, but more commonly to the control male (three out of eight; $37.5 \%$ ) than to males of the same (three out of $39 ; 7.1 \%$ ) or different (five out of 41 ; $10.9 \%$ ) brocket deer lineages (Chi-square $=6.134$, df $2, p=0.047$ ). Only in one case (with partners belonging to different lineages: cytotypes $\mathrm{R}$ and $\mathrm{C}$ ) two copulations took place within the same trial. In order to investigate possible differences between Mazama pairs, the following analyses excluded the control pairs. Latency to mating, i.e. time duration of pre-copula period in those cases

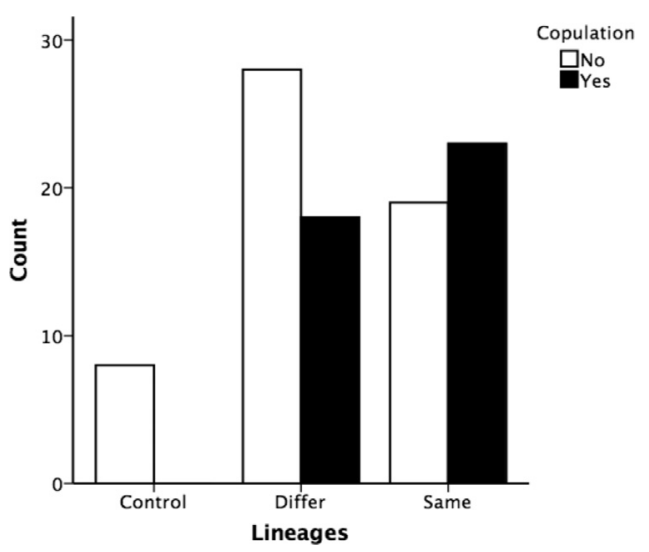

Fig. 1. Number of trials leading or not leading to copulation as a function of whether they were control trials with the white tailed deer, or trials in which male and female red brocket deer belonged to the same or different lineages.

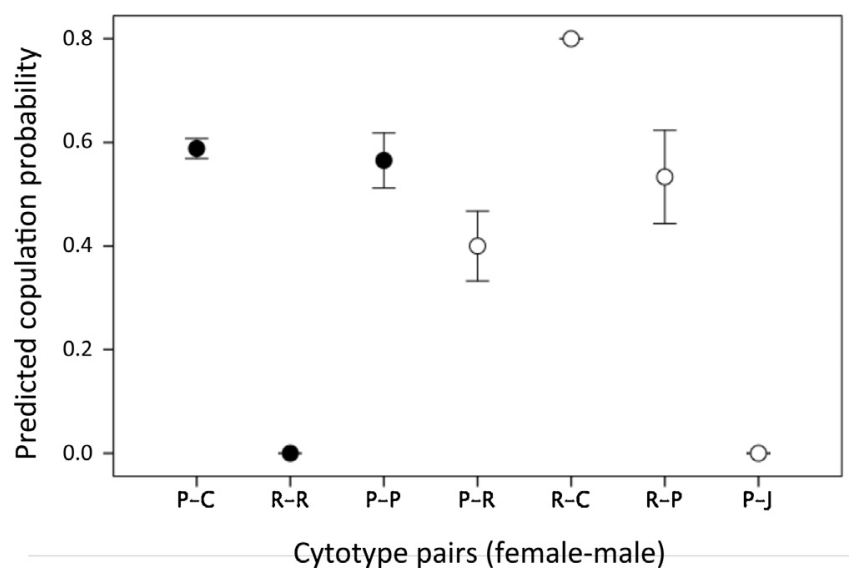

Fig. 2. Copulation probability (mean $\pm 95 \%$ confidence intervals) as predicted from GLMM model of Table 1 for cytotype pairs belonging to the same (black circles) or different lineages (white circles). Cytotype pairs are labeled as female's-male's. Key to cytotypes: P: Paraná; R: Rondonia; C: Carajás; J: Juína.

when copulation occurred, was not different for pairs belonging to the same ( $217.04 \pm 125.68$ SD seconds) or to different lineages $(232.89 \pm 141.50$ SD seconds; $t$-test $t=0.379$, df $39, \mathrm{p}=0.707)$.

We conducted Generalized Linear Mixed Models for copulation as the binary response and individual females nested within males as random subjects, to investigate the potential effect of the type of pairing, as follows: one of them for same vs. different Mazama americana cytotype, another for same $v$ s. different lineage (i.e. group A or B) and the third with all the combinations of cytotype pairs. There were no significant effects in any of them (Table 2; Fig. 2).

Which behaviours were associated with copulation in pairs of the same and different lineages?

The behaviour of males and females during the trial period before any copulation took place were included as predictors in two respective GLMM analyses with Copulation as the dependent variable and individual females nested in males as random subjects, as well as the duration time of this period and lineages of pair members (same or different) as covariates, and all the two-way interactions between lineages and behaviours. In no case was there a significant effect of lineage on copulation probability, although some significant interactions suggest that the relationship between particular behaviours and copulation probability may depend on lineage. 
Table 2

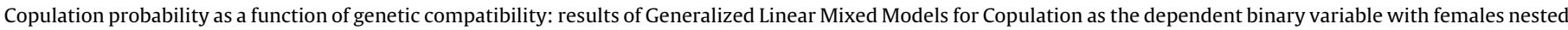

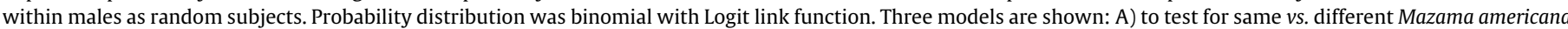
cytotype; B) for same vs. different lineage; and C) with all the combinations of cytotype pairs (female, male; P: Paraná, C: Carajás, J: Juina, R: Rondonia).

\begin{tabular}{|c|c|c|c|c|c|c|}
\hline \multirow[t]{2}{*}{ Model term } & \multirow[t]{2}{*}{ Coefficient } & \multirow[t]{2}{*}{ Std. Error } & \multirow[t]{2}{*}{$t$} & \multirow[t]{2}{*}{ sig. } & \multicolumn{2}{|l|}{$95 \% \mathrm{CI}$} \\
\hline & & & & & Lower & Upper \\
\hline Intercept & -0.409 & 0.628 & -0.651 & 0.518 & -1.667 & 0.850 \\
\hline Cytotype & 0.167 & 0.805 & 0.208 & 0.836 & -1.436 & 1.770 \\
\hline
\end{tabular}

B) GLMM model for same or different lineage (different compared to same, with the latter as the reference value). Random effects: males*females:

Variance $\pm \mathrm{SE}=1.141 \pm 0.776, \mathrm{z}=1.470 ; \mathrm{p}=0.142 . \mathrm{N}=88$ cases. Accuracy of the model $=80.7 \%$

\begin{tabular}{|c|c|c|c|c|c|c|}
\hline \multirow[t]{2}{*}{ Model term } & \multirow[t]{2}{*}{ Coefficient } & \multirow[t]{2}{*}{ Std. Error } & \multirow[t]{2}{*}{$\mathrm{t}$} & \multirow[t]{2}{*}{ sig. } & \multicolumn{2}{|l|}{$95 \% \mathrm{CI}$} \\
\hline & & & & & Lower & Upper \\
\hline Intercept & -0.153 & 0.409 & -0.373 & 0.713 & -1.005 & 0.699 \\
\hline Lineage & -0.261 & 0.755 & -0.346 & 0.731 & -1.767 & 1.245 \\
\hline
\end{tabular}

C) GLMM model for all the combinations of cytotype pairs (female, male; P: Paraná, C: Carajás, J: Juina, R: Rondonia). Random effects: males*females:

Variance $\pm S E=0.877 \pm 0.912, z=0.962 ; p=0.336 . N=88$ cases. Accuracy of the model $=80.7 \%$

\begin{tabular}{|c|c|c|c|c|c|c|}
\hline \multirow[t]{2}{*}{ Model term (sample size) } & \multirow[t]{2}{*}{ Coefficient } & \multirow[t]{2}{*}{ Std. Error } & \multirow[t]{2}{*}{$\mathrm{t}$} & \multirow[t]{2}{*}{ sig. } & \multicolumn{2}{|l|}{$95 \% \mathrm{CI}$} \\
\hline & & & & & Lower & Upper \\
\hline Intercept & -16.566 & & & & & \\
\hline $\mathrm{P}-\mathrm{C}(17)$ & 16.825 & 0.175 & 96.344 & 0.987 & $-32,807.6$ & $32,841.3$ \\
\hline P-J (11) & 0.000 & & & & & \\
\hline $\mathrm{P}-\mathrm{P}(23)$ & 16.469 & 0.552 & 29.830 & 0.413 & $-72,104.0$ & $72,136.9$ \\
\hline P-R (15) & 16.520 & 0.825 & 20.018 & 0.055 & -2.121 & 35.161 \\
\hline $\mathrm{R}-\mathrm{C}(5)$ & 17.952 & & & & & \\
\hline R-P (15) & 16.475 & 0.821 & 20.061 & 0.080 & -16.034 & 48.985 \\
\hline $\mathrm{R}-\mathrm{R}(2)$ & reference pair & & & & & \\
\hline
\end{tabular}

Table 3

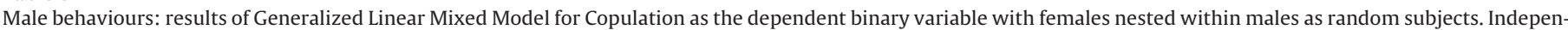

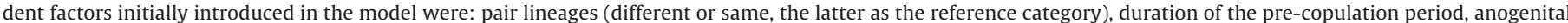

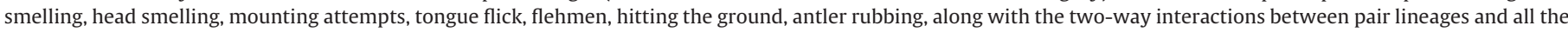

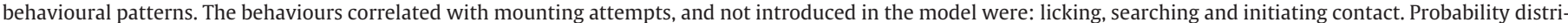

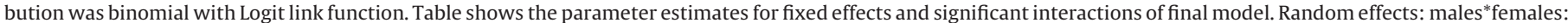
Variance $\pm \mathrm{SE}=3.016 \pm 2.284, \mathrm{z}=1.321 ; \mathrm{p}=1.187 . \mathrm{N}=88$ cases. Accuracy of the model $=90.9 \%$.

\begin{tabular}{|c|c|c|c|c|c|c|}
\hline \multirow[t]{2}{*}{ Model term } & \multirow[t]{2}{*}{ Coefficient } & \multirow[t]{2}{*}{ Std. Error } & \multirow[t]{2}{*}{$\mathrm{t}$} & \multirow[t]{2}{*}{ sig. } & \multicolumn{2}{|l|}{$95 \% \mathrm{CI}$} \\
\hline & & & & & Lower & Upper \\
\hline Intercept & -0.636 & 0.567 & -1.122 & 0.327 & -2.239 & 0.967 \\
\hline Lineage & -0.910 & 1.163 & -0.782 & 0.444 & -3.340 & 1.521 \\
\hline Duration & -0.008 & 0.002 & -3.399 & 0.001 & -0.013 & -0.004 \\
\hline Anogenital & 0.079 & 0.045 & 1.778 & 0.098 & -0.017 & 0.175 \\
\hline Head & 0.032 & 0.014 & 2.362 & 0.043 & 0.001 & 0.063 \\
\hline Mounts & 0.202 & 0.071 & 2.847 & 0.006 & 0.061 & 0.343 \\
\hline Tongue & -0.031 & 0.054 & -0.577 & 0.566 & -0.139 & 0.077 \\
\hline Flehmen & 0.709 & 0.264 & 2.686 & 0.011 & 0.171 & 1.247 \\
\hline Hitting & 0.179 & 0.125 & 1.434 & 0.156 & -0.070 & 0.429 \\
\hline Antler rubb. & -0.000 & 0.009 & -0.052 & 0.959 & -0.019 & 0.018 \\
\hline Lineage differ*Anogenital & 0.088 & 0.067 & 1.310 & 0.205 & -0.052 & 0.227 \\
\hline Lineage differ*Mounts & -0.293 & 0.083 & -3.548 & 0.001 & -0.458 & -0.128 \\
\hline Lineage differ*Tongue & 0.115 & 0.068 & 1.689 & 0.097 & -0.022 & 0.252 \\
\hline Lineage differ*Antler rubb. & 0.045 & 0.019 & 2.328 & 0.023 & 0.006 & 0.084 \\
\hline
\end{tabular}

For males, Mounting attempts, Licking, Searching and Initiating contact were highly correlated. Among them, the best model resulted when including Mounting attempts. The results are shown in Table 3. The random effect males*females was not significant. Head smelling, mounting attempts and flehmen were positively related to copulation probability. We found two significant interactions, indicating a negative effect of mounting when lineages were different with respect to same, and a positive effect of antler rubbing when lineages differed.

For females, on one hand Initiating contact, Search and Licking, and on the other hand Anogenital and Head smelling, were corre- lated. In the model, we introduced Initiating contact and Anogenital smelling along with the remaining non-correlated behaviours. The results are shown in Table 4 . The random effect males*females was not significant. Copulation was positively related to tail fanning and also very strongly to squatting by females. We found three significant interactions. On one hand, initiating contact appeared positively related to copulation when partners belonged to different lineages. On the other hand, tail fanning and squatting showed a negative coefficient when lineages differed with respect to the cases when both partners belonged to the same lineage. 
Table 4

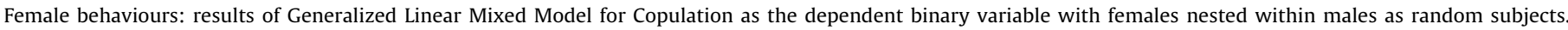

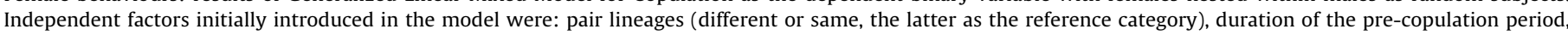

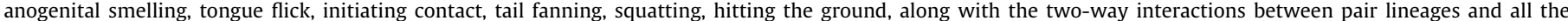

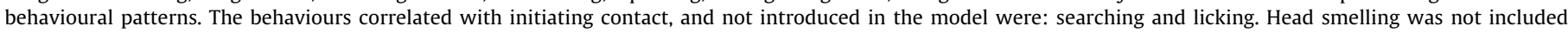

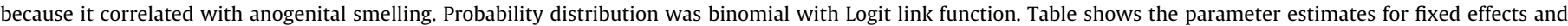
significant interactions of final model. Random effects: males*females: Variance $\pm S E=2.336 \pm 1.637, z=1.426 ; p=1.154$. N $=88$ cases. Accuracy of the model $=85.2 \%$.

\begin{tabular}{|c|c|c|c|c|c|c|}
\hline \multirow[t]{2}{*}{ Model term } & \multirow[t]{2}{*}{ Coefficient } & \multirow[t]{2}{*}{ Std. Error } & \multirow[t]{2}{*}{$\mathrm{t}$} & \multirow[t]{2}{*}{ sig. } & \multicolumn{2}{|l|}{$95 \% \mathrm{CI}$} \\
\hline & & & & & Lower & Upper \\
\hline Intercept & -0.853 & 0.461 & -1.851 & 0.135 & -2.110 & 0.404 \\
\hline Lineage & 0.564 & 0.946 & 0.596 & 0.557 & -1.403 & 2.532 \\
\hline Duration & -0.004 & 0.002 & -2.361 & 0.021 & -0.007 & -0.001 \\
\hline Anogenital & 0.042 & 0.034 & 1.224 & 0.225 & -0.026 & 0.111 \\
\hline Tongue & 0.092 & 0.060 & 1.524 & 0.132 & -0.028 & 0.212 \\
\hline Initiating & -0.661 & 0.538 & -1.228 & 0.223 & -1.733 & 0.411 \\
\hline Tail & 0.069 & 0.024 & 2.874 & 0.005 & 0.021 & 0.117 \\
\hline Squatting & 13.133 & 0.775 & 16.939 & $<0.001$ & 11.085 & 15.181 \\
\hline Hitting & -4.300 & 0.223 & -19.227 & 0.296 & $-1,905.1$ & $1,896.5$ \\
\hline Lineage differ*Initiating & 2.341 & 0.778 & 3.011 & 0.004 & 0.792 & 3.890 \\
\hline Lineage differ*Tail & -0.066 & 0.037 & -1.817 & 0.073 & -0.139 & 0.006 \\
\hline Lineage differ*Squatting & -13.473 & 2.464 & -5.467 & $<0.001$ & -18.432 & -8.514 \\
\hline Lineage differ*Hitting & 4.428 & 0.222 & 19.154 & 0.307 & $-2,637.7$ & $2,646.2$ \\
\hline
\end{tabular}

\section{Discussion}

We have shown that red brocket deer females never copulated with the control white-tailed buck and that they did not show statistically significant differences in copulation probability with males belonging to their own or to different genetic lineages, for which post-zygotic incompatibility has been demonstrated. Our results also evidenced that despite the captive conditions and the limited available space for females to escape from the courting males, females were able to reject males even by behaving aggressively. Since we never continued the trial after female aggressive behaviour, copulations may be interpreted as actual acceptances of the mate. The contrasting behaviour towards Odocoileous compared to that to the other red brocket deer of either lineage supports the absence of a clear premating barrier between both lineages, rather than it being a general characteristic of female red brocket deer behaviour.

Latency to mating has been used as a measure of preference, especially in no-choice tests (e.g. Shackleton et al., 2005). Our analyses showed that latency to mating did not differ when members of the pair belonged to the same or to different lineages, which also points to a lack of preference to avoid the incompatibility between lineages.

We were able to identify some behaviours that related to copulation probability in males and females. For males, they performed more flehmen behaviour, head smelling and mounting attempts in trials that ended with copulation. Other behaviours such as licking, searching and initiating contact may also be involved due to their correlation with mounting. Thus, in successful trials males had been more eager to perceive chemical compounds from the female by flehmen and smelling in agreement with the role of olfactory signals in courtship (Price, 2008; Brennan, 2010), and had performed more approaching behaviours and mounting attempts. But also, although copulation probability in the trial did not depend on whether the partners belonged to the same or different lineage, approaches and mountings were less successful when the female belonged to a different lineage. This suggests that females may show some preference for same-lineage males. The behaviour of females also suggests some discrimination. Our results show that tail fanning and squatting were important for copulation to occur in the trial, but that this relationship was not so when the male belonged to a different lineage. By these behaviours, females emit olfactory signals, mainly through the urine, that presumably communicate their situation regarding oestrus and willingness to mate
(Brennan, 2010; Bradbury and Vehrencamp, 2011). Hence, these chemical emissions may encode different meanings and may relate positively or negatively with copulation probability, which in our results seems to be related to lineage equality between pair members. It is also remarkable that initiating contact by the female, and likely its correlated behaviours searching and licking, appeared positively related to copulation when lineages differ between pair members, suggesting a role of female behaviour for acceptance of some partners despite their belonging to different lineages.

In most mammals, males are expected to be less selective than females when seeking copulations. This is so because females incur higher costs than males from wrong matings, and because for males rejecting a current mating in the hope of better future opportunities is not easily selected for (see e.g. Barry and Kokko, 2010). Our results suggest that copulation between lineages may depend more on female behaviour approaching some males and then male behaviour might be influenced by female communication on her willingness to mate. However, we should take these behavioural results with caution when trying to generalize them from a sample of individuals into the whole species. We are working with the biggest stock of red brocket deer in the world, but even so we must be aware of its limitations, as for any study with a limited sample of captive individuals.

A central question arising from our results is why there is not a pre-mating barrier between these lineages that can occur in sympatry and would produce unsuccessful hybrids. Evidence for interspecific mating and breeding are common among the Cervidae species. For instance, between sika Cervus nippon and red deer C. elaphus (Biedrzycka et al., 2012; Putman and Hunt, 1993; Senn and Pemberton, 2009), and also between red deer and wapiti $C$. canadensis (Geist, 1998; Ludt et al., 2004). However, distribution areas in those cases are not sympatric as for the red brocket deer, so that selection may have had lower chances to favour isolation mechanisms.

Random changes in chromosomes can occur within short periods of time (e.g. Britton-Davidian et al., 2000). Divergence between both red brocket deer lineages can be dated at less than two MYA (Duarte et al., 2008), so one possibility is that time has been too short for selection to mold mating preferences for compatible mates. The high resemblance between members of both lineages, indistinguishable for humans, may contribute to maintain acceptance. Mating preferences may evolve by phenotype matching, whereby individuals prefer a mate whose phenotype is similar to their own (Lacy and Sherman, 1983), which may favour 
inter-lineage mating in our case and interspecific mating in morphologically convergent species (e.g. Ptacek, 1998).

But there are also forces acting against selection for mate avoidance and hence in favour of the maintenance of a wider range of acceptance. Rejection of potential mates entails costs, for example when males and females lose time, energy and mating opportunities when suitable partners are wrongly avoided. Male harassment may also increase the costs of mate rejection, so that females may be forced to accept copulations to save time, energy and risk of injuries from the males. Especially if the chances for inter-lineage encounters are not very high (rare enemy effect: Dawkins, 1982), female rejection of courting males may not be readily favoured.

Selection should favour mate discrimination and rejection if leading to the allocation of significant maternal resources into unviable or low successful offspring (Servedio and Noor, 2003). However, the existence of effective barriers either at postcopulatory-prezygotic phase or at an early postzygotic stage when little investment has been allocated to the new embryo by the female, can reduce the strength of selection for precopulatory barriers, i.e. favour female acquiescence against male coercion (Parker and Birkhead, 2013). We have seen in at least one case in our experiments that within each ovulation females can accept more than one copulation. This opens the chances for selection to produce post-copulatory pre-zygotic mechanisms of sperm selection for compatibility (Eberhard, 1996; Gadella, 2010; Parker, 1970). A remarkable study on pre-mating barriers between two species of crickets (Veen et al., 2011) showed that female discrimination was asymmetric, with G. campestris females never mating heterospecifically while the more polyandrous $G$. bimaculatus mating heterospecifically, probably related to higher chances of postmating barriers.

In a recent study with brocket deer of the grey clade, interspecific matings between M. gouazoubira and M. nemorivaga occurred in almost $36 \%$ of trials (Carranza et al., 2017). These species are morphologically convergent and also show several copulations within the same ovulation, so chances for post-mating sexual selection appear also high (Carranza et al., 2017). Postmating-prezygotic mechanisms have been shown to effectively reduce gene flow and thus act to maintain species boundaries if fertilization success in conspecific matings is relatively greater than that in heterospecific ones (Howard et al., 1998, 2009). Brocket deer species share the common feature of being solitary forest dwellers. Sexual selection is not strong at the precopulatory stage in solitary species, either because male-male direct encounters are not so common and/or because for females there are difficulties in assessing male quality and competitive ability without simultaneous comparison (see e.g. Pfennig, 1998). Such conditions hamper the evolution of specific signals for mate assessment, thus leading to stronger selection for post-mating sex-traits (ungulates: Ferrandiz-Rovira et al., 2014; howler monkeys: Dunn et al., 2015). However, the study of potential post-copulatory pre-zygotic barriers is pending in red brocket deer.

Our results may have relevant implications for conservation. The evolutionary process of sympatric speciation entails the occurrence of hybridization events that constitute the basis for selection to produce isolation reinforcement (Servedio and Noor, 2003). This selective process tends to produce a natural matching between the probability of inter-lineage contacts and the strength of isolation mechanisms. However, the alteration of habitats by human activity may lead to rapid changes in species distribution and contacts, along with strong reductions of population size in evolutionary significant units. With isolation mechanisms not fully developed, human-induced decoupling between geographical distributions and reproductive barriers can potentially lead to hybridization events that may put evolutionary units at risk. To date, the specific geographical distribution of every red brocked deer cytotype is not known, only isolated locations have been registered of each of them in previous studies (Abril et al., 2010). However, it seems that there are no relevant geographical barriers that may impede the encounter among animals from different cytotypes.

Lineages included in this study may be considered as different species, since high levels of molecular and cytogenetic differentiation have been shown between them (Duarte et al., 2008). Similarly, from a reproductive point of view, the existence of well-established post-zygotic isolation between the most distant karyotype lineages has been also proved (Cursino et al., 2014; Salviano et al., 2017). All these results along with the findings of this study on the absence of clear pre-zygotic barriers among cytotypes have important implications for the conservation of these species. It has been shown that extinction risk through hybridization is lower in presence of pre-mating reproductive barriers (Todesco et al., 2016). Hence, the merging of red brocked deer lineages and the emergence of maladaptive hybrids may lead to unfavourable conservation status or even local extinction of some populations, although information of geographical locations where these processes may happen is still lacking.

Further work should focus on the significant evolutionary units of red brocket deer currently occurring in nature, on a better delimitation of their distribution areas and on estimating the probability of inter-lineage mating contacts and hybridization, on their ecology and mating behaviour in the wild, and on the role of postcopulatory pre-zygotic barriers to maintain the isolation between lineages and species.

\section{Acknowledgements}

We thank Antonio Carlos L. Andrade, Gessica C.H. Rodrigues and all personnel at NUPECCE for help during the experiments with the deer. C. Mateos provided statistical advice. Flavio Ford revised the English style. Financial support was from CAPES/CNPq (project A038_2013 to J.M.B.D. and J.C) and FAPESP (proc. 10/50748-3).

\section{References}

Abril, V.V., Carnelossi, E.A.G., Gonzales, S., Duarte, J.M.B., 2010. Elucidating the evolution of the red brocket deer Mazama americana complex (Artiodactyla; Cervidae). Cytogenet. Genome Res. 128, 177-187.

Allen, J.A., 1915. Notes on American deer of the genus Mazama. Bull. Am. Mus. Nat Hist. 34, 521-553

Amato, G., Egan, M.G., Schaller, G.B., 2000. Mitochondrial DNA variation in Muntjac: evidence for discovery, rediscovery, and phylogenetic relationships. In: Schaller, G.B., Vrba, E.S. (Eds.), Antelopes, Deer, and Relatives: Fossil Record Behavioural Ecology, Systematics, and Conservation. Yale University Press.

Andersson, M.A., 1994. Sexual Selection. Princeton University Press, Princeton, NJ, USA.

Aquino, C.I., Abril, V.V., Duarte, J.M.D., 2013. Meiotic pairing of B chromosomes multiple sexual system, and Robertsonian in the red brocket deer Mazama Americana (Mammalia, Cervidae) Genet. Mol. Res. 12, 3566-3574.

Baker, R.J., Bickham, J.W., 1986. Speciation by monobrachial centric fusions. Proc. Natl. Acad. Sci. U. S. A. 83, 8245-8248.

Barry, K.L., Kokko, H., 2010. Male mate choice: why sequential choice makes its evolution difficult. Anim. Behav. 80, 163-169.

Biedrzycka, A., Solarz, W., Okarma, H., 2012. Hybridization between native and introduced species of deer in Eastern Europe. J. Mammal. 93, 1331-1341.

Bodmer, R.E., 1997. Ecologia e conservação dos veados mateiro e catingueiro na Amazônia. In: Duarte, J.M.D. (Ed.), Biologia e Conservação de Cervídeos Sul-Americanos: Blastocerus, Ozotozeros e Mazama. Fundação de Estudos e Pesquisas em Agronomia. Medicina Veterinária e Zootecnia Jaboticabal, São Paulo Brazil.

Bradbury, J.V., Vehrencamp, S.L., 2011. Principles of Animal Communication. Sinauer Associates, Sunderland MA.

Brennan, P.A., 2010. Pheromones and mammalian behavior. In: Menini, A. (Ed.), The Neurobiology of Olfaction. CRC Press/Taylor \& Francis, Boca Raton, Florida.

Britton-Davidian, J., Catalan, J., Ramalhinho, M.G., Ganem, G., Auffray, J.-C., Capela, R., Biscoito, M., Searle, J.B., Mathias, M.L., 2000. Rapid chromosomal evolution in island mice. Nature 403, 158.

Cabrera, A., 1960. Catálogo de los mamíferos de América del Sur. Revista Museo Argentino Bernardino Rivadavia 4, 309-732. 
Carranza, J., Roldán, M., Carvalho-Peroni, E.F., Duarte, J.M.B., 2017. Weak premating isolation between two parapatric brocket deer species. Mamm. Biol. 87, 17-26, http://dx.doi.org/10.1016/j.mambio.2017.02.009.

Coyne, J.A., Orr, H.A., 2004. Speciation. Sinauer Associates U.S.A, Sunderland, MA.

Curlewis, J.D., Loudon, A.S.I., Coleman, A.P.M., 1988. Oestrous cycles and the breeding season of the Père David's deer hind (Elaphurus davidianus). J. Reprod. Fertil. 82, 119-126.

Cursino, M.S., Salviano, M.B., Abril, V.V., Zanetti, E.S., Duarte, J.M.B., 2014. The role of chromosome variation in the speciation of the red brocket deer complex: the study of reproductive isolation in females. BMC Evol. Biol. 14, 40.

Czernay, S., 1987. Spiesshirsche und Pudus. Die Neue Brehm-Bücherei 581, 1-84.

Dawkins, R., 1982. The Extended Phenotype: The Long Reach of the Gene. Oxford University Press, Oxford, UK.

Dobzhansky, T., 1937. Genetics and the Origin of Species. Columbia University Press, New York.

Dougherty, L.R., Shuker, D.M., 2015. The effect of experimental design on the measurement of mate-choice: a meta-analysis. Behav. Ecol. 26, 311-319.

Duarte, J.M.B., Jorge, W., 2003. Morphologic and cytogenetic description of the small red brocket (Mazama bororo Duarte, 1996) in Brazil. Mammalia 67, 403-410.

Duarte, J.M.B., Merino, M.L., 1997. Taxonomia e evolução. In: Duarte, J.M.B. (Ed.) Biologia e Conservacao de Cervideos Sul-americanos: Blastocerus, Ozotoceros e Mazama. FUNEP, Jaboticabal, Brazil, pp. 1-21.

Duarte, J.M.B., González, S., Maldonado, J.E., 2008. The surprising evolutionary history of South American deer. Mol. Phylogenet. Evol. 49, 17-22.

Duarte, J.M.B., 1996. Guia de Identificação de Cervídeos Brasileiros. Jaboticabal, Brazil, FUNEP.

Dunn, J.C., Halenar, L.B., Davies, T.G., Cristobal-Azkarate, J., Reby, D., Sykes, D., Dengg, S., Fitch, W.T., Knapp, L.A., 2015. Evolutionary trade-off between vocal tract and testes dimensions in howler monkeys. Curr. Biol. 25, 1-6.

Eberhard, W.G., 1996. Female Control: Sexual Selection by Cryptic Female Choice. Princeton Univ, Press, Princeton, NJ.

Eisemberg, J.F., 1989. Mammals of the Neotropics, vol. I. University of Chicago Press, Chicago (pp 449).

Emmons, L.H., 1990. Neotropical Rainforest Mammals, a Field Guide. University of Chicago Press, Chicago (pp 281).

Escobedo-Morales, L., Mandujano, S., Eguiarte, L.E., Rodríguez-Rodríguez, M.A. Maldonado, J.E., 2016. First phylogenetic analysis of Mesoamerican brocket deer Mazama pandora and Mazama temama (Cetartiodactyla: cervidae) based on mitochondrial sequences: implications on Neotropical deer evolution. Mamm. Biol. 81, 303-313.

Ferrandiz-Rovira, M., Lemaître, J.F., Lardy, S., López, B.C., Cohas, A., 2014. Do preand post-copulatory sexually selected traits covary in large herbivores? BMC Evol. Biol. 14, 79.

Futuyma, D.J., 2005. Evolution. Sinauer \& Associates, Inc., Massachusetts.

Gadella, B.M., 2010. Interaction of sperm with the zona pellucida during fertilization. Soc. Reprod. Fertil. Suppl. 67, 267-287.

Geist, V., 1998. Deer of the World: Their Evolution, Behaviour, and Ecology. Stackpole Books, Mechanicsburg.

Heckeberg, N.S., Erpenbeck, D., Wörheide, G., Rössner, G.E., 2016. Systematic relationships of five newly sequenced cervid species. PeerJ 4, http://dx.doi.org/ 10.7717/peerj.2307 (e2307).

Howard, D.J., Gregory, P.G., Chu, J.M., Cain, M.L., 1998. Conspecific sperm precedence is an effective barrier to hybridization between closely related species. Evolution 52, 511-516.

Howard, D.J., Palumbi, S.R., Birge, L.M., Manier, M.K., 2009. Sperm and speciation. In: Birkhead, T.R., Hosken, D.J., Pitnick, S. (Eds.), Sperm Biology: An Evolutionary Perspective. Elsevier, Oxford, pp. 367-403.

Huang, L., Wang, J., Nie, W., Su, W., Yang, F., 2006. Tandem chromosome fusions in karyotypic evolution of Muntiacus: evidence from $M$ feae and $M$. gongshanensis Chromosome Res. 14, 637-647.

Irwin, D.E., Irwin, J.H., Price, T.D., 2001. Ring species as bridges between microevolution and speciation. Genetica 112-113, 223-243.

Johnstone, R.A., 1997. The evolution of animal signals. In: Krebs, J.R., Davies, N.B (Eds.), Behavioural Ecology: An Evolutionary Approach. , 4th ed. Blackwell Scientific, Oxford, pp. 155-178.

Kokko, H., Brooks, R., Jennions, M.D., Morley, J., 2003. The evolution of mate choice and mating biases. Proc. Biol. Sci. 270, 653-666.

Lacy, R.C., Sherman, W., 1983. Kin recognition by phenotype matching. Am. Nat. $121,489-512$
Ludt, C.J., Schroeder, W., Rottmann, O., Kuehn, R., 2004. Mitochondrial DNA phylogeography of red deer (Cervus elaphus). Mol. Phylogenet. Evol. 31, 1064-1083.

Mayr, E., 1963. Animal Species and Evolution. Harvard University Press, Cambridge.

Morales-Piñeyrua, J.T., Ungerfeld, R., 2012. Pampas deer (Ozotoceros bezoarticus) courtship and mating behavior. Acta Vet. Scand. 54, 60-66.

Parker, G.A., Birkhead, T., 2013. Polyandry: the history of a revolution. Philos. Trans. R. Soc. Lond. B 368, 20120335

Parker, G.A., 1970. Sperm competition and its evolutionary consequences in insects. Biol. Rev. Camb. Philos. Soc. 45, 525-567.

Pfennig, K.S., 1998. The evolution of mate choice and the potential for conflict between species and mate-quality recognition. Philos. Trans. R. Soc. Lond. Bio. 265, 1743-1748.

Piálek, J., Albrecht, T., 2005. Choosing mates: complementary versus compatible genes. Trends Ecol. Evol. 20 (2), 63.

Price, E.O., 2008. Principles and Applications of Domestic Animal Behavior An Introductory Text. CABI, Cambrige University Press, Cambridge, UK.

Ptacek, M.B., 1998. Interspecific mate choice in sailfin and shortfin mollies. Anim. Behav. 56, 1145-1154

Ptacek, M.B., 2000. The role of mating preferences in shaping interspecific divergence in mating signals in vertebrates. Behav. Process. 51, 111-134.

Putman, R.J., Hunt, E.J., 1993. Hybridization between red and sika deer in Britain. Deer 9, 104-110.

Rossi, R.V., 2000. Taxonomia de Mazama Ranfinesque, 1817 do Brasil (Artyodactyla, Cervidae). Universidade de São Paulo, São Paulo, Brazil (Msc, Thesis).

Ryan, M.J., Tailor, R.C., 2015. Measures of mate choice: a comment on Dougherty and Shuker. Behav. Ecol. 26, 323-324.

Salviano, M.B., Cursino, M.S., Zanetti, E.D.S., Abril, V.V., Duarte, J.M.B., 2017. Intraspecific chromosome polymorphisms can lead to reproductive isolation and speciation: an example in red brocket deer (Mazama americana). Biol. Reprod. 96 (6), 1279-1287, http://dx.doi.org/10.1093/biolre/iox041.

Samsudewa, D., Capitan, S.S., 2011. Reproductive behaviour of Timor deer (Rusa timorensis). Wartazoa 21, 108-113.

Senn, H.V., Pemberton, J.M., 2009. Variable extent of hybridization between invasive sika (Cervus nippon) and native red deer (C. elaphus) in a small geographical area. Mol. Ecol. 18, 862-876.

Servedio, M.R., Noor, M.A.F., 2003. The role of reinforcement in speciation: theory and data. Annu. Rev. Ecol. Syst. 34, 339-364.

Shackleton, M.A., Jennions, M.D., Hunt, J., 2005. Fighting success and attractiveness as predictors of male mating success in the black field cricket, Teleogryllus commodus: the effectiveness of no-choice tests. Behav. Ecol. Sociobiol. 58, 1-8.

Shah, K.B., Tripathy, S., Suganthi, H., Rudraiah, M., 2014. Profiling of luteal transcriptome during prostaglandin F2-alpha treatment in buffalo cows: analysis of signaling pathways associated with luteolysis. PLoS One 9 (8), e104127.

Todesco, M., Pascual, M.A., Owens, G.L., et al., 2016. Hybridization and extinction. Evol. Appl. 9, 892-908.

Tomkins, T., Bryant, M.J., 1974. Oestrous behaviour of the ewe and the influence of treatment with progestagen. J. Reprod. Fertil. 41, 121-132.

Trivers, R.L., 1972. Parental investment and sexual selection. In: Campbell, B. (Ed.), Sexual Selection and the Descent of Man, 1871-1971. Aldine-Atherton, Chicago, IL, pp. 136-179.

Varela, D.M., Trovati, R.G., Guzmán, K.R., Rossi, R.V., Duarte, J.M.B., 2010. Red brocket deer-Mazama americana. In: Duarte, J.M.B., González, S. (Eds.), Neotropical Cervidoloy: Biology and Medicine of Latin American Deer. FUNEP/IUCN, Jaboticabal, pp. 151-159.

Veen, T., Faulks, J., Rodríguez-Muñoz, R., Tregenza, T., 2011. Premating reproductive barriers between hybridising cricket species differing in their degree of polyandry. PLoS One 6, 1-7.

Wagner, C.E., Harmon, L.J., Seehausen, O., 2012. Ecological opportunity and sexual selection together predict adaptive radiation. Nature 487, 366-369.

Zanetti, E.S., Duarte, J.M.B., Polegato, B.F., Garcia, J.M., Canola, J.C., 2010. Assisted reproductive technology. In: Duarte, J.M.B., Gonzáles, S. (Eds.), Neotropical Cervidology. FUNEP, Jaboticabal, pp. 255-270.

van Doorn, G., Edelaar, P., Weissing, F.J., 2009. On the origin of species by natural and sexual selection. Science 326, 1704-1707. 